\title{
Intellectual Property Protection, Regulation and Innovation in Developing Economies: \\ The Case of Indian Pharmaceutical Industry
}

\section{Rakesh Basant}

W.P. No. 2010-11-02

November 2010

The main objective of the working paper series of the IIMA is to help faculty members, research staff and doctoral students to speedily share their research findings with professional colleagues and test their research findings at the pre-publication stage. IIMA is committed to maintain academic freedom. The opinion(s), view(s) and conclusion(s) expressed in the working paper are those of the authors and not that of IIMA.

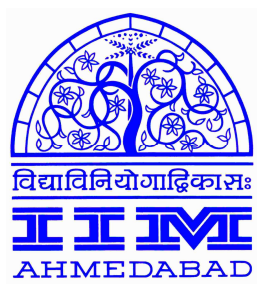

INDIAN INSTITUTE OF MANAGEMENT AHMEDABAD-380 015 INDIA 


\title{
Intellectual Property Protection, Regulation and Innovation in Developing Economies - The Case of Indian Pharmaceutical Industry
}

\author{
Rakesh Basant ${ }^{1}$ \\ Indian Institute of Management, Ahmedabad \\ Email: rakesh@iimahd.ernet.in
}

\begin{abstract}
Historically, nations have modified their IP policies to support their development agenda. With the advent of TRIPS, the ability of countries to choose between different IP policy options has reduced considerably but some flexibility remains. Countries have tried to utilize this flexibility for their advantage but in certain respects the choices are difficult. In recent years, certain elements of the new IP regime in India have been vigorously debated in the context of the TRIPS mandated IP policy changes. Given the complex interface between economic development and IP regimes, a variety of arguments have been deployed to argue in favour or against these elements. The paper argues that an evaluation of the IP regime and regulation in developing countries needs to be done in the context of how they facilitate capability building especially through participation of domestic firms in global $R \& D$ and production networks. Opportunities for domestic firms to participate in global networks depend on a variety of inter-related factors like emerging technology regimes, changes in global industrial structures, strategies followed by MNCs and capabilities and strategies of domestic firms with respect to innovation. Consequently, the fine-tuning of the IP regime would require an understanding of these developments as well, often in the context of a specific sector. The paper uses this broad heuristic framework to analyze emerging IP policy needs for the Indian pharmaceutical sector and the role of other types of regulation. In the process it also provides some insights on how developing countries with decent technological capabilities can exploit regulatory flexibilities available in the post-TRIPS scenario.
\end{abstract}

\footnotetext{
${ }^{1}$ This paper builds on some ideas and preliminary analysis contained in Basant (2006). It is part of a larger project supported by the Wadhwani Foundation. The author is grateful to two anonymous referees for excellent comments and to Sheetal Menon for competent research assistance. Thanks are also due to Kishan Bhat for sharing data and insights. The usual disclaimers apply.
} 


\section{Introduction}

The linkages between intellectual property rights (IPRs) regimes and economic development 'are complex and difficult to measure' (Maskus 2008: 50). IPRs affect the development process not only through their impact on activities relating to making (e.g., R\&D), buying (e.g., licensing) and copying of technology but also through their impact on investment (both domestic and foreign) and trade (Greenhalgh and Rogers, 2010). Absence of robust empirical evidence makes it unclear if economic development precedes or follows setting up of stringent IP protection. There is enough evidence to suggest, however, that nations have tried to shape IP regimes according to their development needs. In general, there has been a tendency by nations to adopt more stringent IP regimes as incomes rise. ${ }^{2}$ The flexibility that developing countries have in the post-TRIPS world is much lower than what was available earlier. However, the need to fine-tune IP policies for a nation's development requirements is still recognized.

It is increasingly been argued that developing countries with somewhat higher technological capabilities may have significantly different IP policy needs as compared to those where technological proficiency is relatively low (Basheer and Primi, 2009). The IP policy dilemmas of BRICS countries, for example, are likely to be different from the nations in sub-Saharan Africa. In what way are these dilemmas different and how should these be resolved? Answers to these questions are not straightforward for policy makers. In an interesting empirical study Falvey et al (2006), have suggested that unlike high and low income countries, middle income countries do not benefit from stronger IP regimes as the positive effects via FDI and trade get nullified by the negative effects due to inability to imitate and use knowledge. By this logic a stronger IP regime in BRICS like nations with decent technological capabilities is not desirable. But such a conclusion may be inappropriate if elements of the strong IP regimes facilitate the capability building process. However, apart from the tenuous links between IP policies and economic development, it is well known that the technological capability building processes

${ }^{2}$ See .Mercurio (2010) provide for a short review of studies of IPRs in different countries. Also see papers in Odagiri et.al (eds), (2010). 
are very complex and IP protection is only one of the factors that contribute to this process; nations rely on diverse mechanisms to build capabilities and several policies (including trade, industry, competition, education) can influence these mechanisms. Consequently, to understand the role of IPR in 'catch-up' process requires in-depth analyses of individual nations and sectors (Odagiri et.al. 2010). On the basis of available evidence on, this paper attempts such a task for India in the context of pharmaceutical industry and explores the emerging IP policy needs for the country. In the process it also tries to identify factors that may be relevant for developing an appropriate IP policy for newly emerging economies.

The rest of the paper is divided into five sections. Section 2 discusses briefly the elements that can constitute the analytical framework for evaluating the contours of IP policy. Section 3 highlights the key changes in drug development technologies that have given rise to new niches for participation in the R\&D networks. The following section builds on this discussion to summarize the opportunities in the pharmaceutical-biotech sector that are being exploited both by Indian as well as the multinational firms. This section also provides some evidence on strategies followed by Indian and multinational firms in the pharmaceutical industry. In the context of these developments, Section 5 reviews the existing IPR laws to evaluate if these laws can potentially constrain the exploitation of the emerging opportunities in the sector by Indian and multinational firms. The final section provides some ideas on how the IP regime could be modified and how other types of regulation can complement these initiatives to address the multiplicity of objectives that the policy makers need to grapple with in the current stage of India's economic development.

\section{A Heuristic Framework for Evaluating IP Policy Needs}

Evaluation of IP policy needs is contingent on the role/s that one expects the policy to play. Even after developing countries introduced a 'TRIPS-compatible' intellectual property rights (IPR) regime, the debates around the fine-tuning of this regime have continued. In the case of India, for example, which affected such a regime in 2005, the controversies have been most prominent in the context of pharmaceutical industry wherein the changes in the Indian IP regime have probably been most 
dramatic with the introduction of product patents. Apparent in these debates is the expectation that the IP regime should not only create incentives for investments in inventive $\&$ innovative activities and facilitate technology disclosure, arguably the primary objectives of IPRs, but also help bring in foreign direct investment, enhance competitive pressures, keep prices in check and so on. Given such multiplicity of objectives, it becomes virtually impossible to assess the appropriateness of the IP regime. Moreover, in such a scenario, the potential of other types of regulation addressing some of these objectives and complementing IP policy typically remains under-explored.

Building technological capabilities is critical for economic development. Recent studies have shown that participation in global production/innovation networks can create significant opportunities to build these capabilities. Ernst (2002), for example, has argued that developing economies need to blend domestic and international sources of knowledge to create/develop national production and innovation systems and emerging global production/innovation networks provide new opportunities for reverse knowledge outsourcing. ${ }^{3}$ Studies have highlighted the relevance of networks in building dynamic capabilities by exploring the complex interface between knowledge flows (due to networks) and firm level capabilities. ${ }^{4}$ Consequently, evaluation of the IP regime and regulation in developing countries needs to be done in the context of how they facilitate capability building especially through participation of domestic firms in global R\&D and production networks.

Opportunities for domestic firms to participate in global networks can depend on a variety of inter-related factors. These may include emerging technology regimes, changes in global industrial structures, strategies followed by MNCs and capabilities and strategies of domestic firms with respect to innovation related activities. In the context of pharmaceutical and biotechnology industry for example,

\footnotetext{
${ }^{3}$ Also see Basant (2004) and Ernst and Kim (2002) for similar arguments.

${ }^{4}$ See Rothaermel and Hess (2007) for a very interesting study of such interfaces in the pharmaceutical and biotechnology industries.
} 
participation in global production and R\&D networks and the associated capability building possibilities are likely to be affected by:

- Emerging changes in drug development technologies;

- Changes in the global structure of pharmaceutical and biotech industry;

- Strategies of multinational firms in drug development, clinical trials and manufacturing; and

- Evolving capabilities/strategies of domestic firms in the industry.

Provision of incentives for innovation is the main objective of an IP regime. The ability of firms in developing economies to undertake radical innovations is very limited; they are more likely to be engaged in incremental innovations. The role of incremental innovations in technological change and economic development is well known. ${ }^{5}$ Given changes in technology regimes, industry structures and MNC strategies, domestic firms can potentially enhance their participation in global production and innovation networks through the development of incremental innovations. An IP regime that fosters incremental innovation may allow firms to benefit by affording protection to small incremental improvements on existing intellectual property that can in turn be used by owners of the IP to move up the technological value chain. In addition, the IPR framework directly affects the ability of firms to take advantage of commercial opportunities that require the existence of a suitable IP regime before commercial/service agreements can be reached with potential clients. Such market creating potential of the IPR framework can also impinge on the ability of small firms to enter into IP intensive activities as subcontractors and licensees.

While India has made its IP regime TRIPS compatible, it is not entirely clear if the new regime would facilitate the participation of Indian companies in the knowledge intensive global production and $R \& D$ networks and if it is appropriate for an economy that is expected to grow rapidly enlarging the demand for a variety of

\footnotetext{
${ }^{5}$ See US-India Business Council and Coalition for Healthy India (2009) for a discussion of the role of incremental innovation in the pharmaceutical and biotech industries.
} 
products and services. The analysis in the paper is built on the premise that ceteris paribus participation of Indian firms in IP creation and participation in knowledge intensive activities is desirable. If changes in technology and global industrial structure are creating opportunities for firms to engage such activities, IP policies should positively discriminate in favour of such participation. Similarly, if the domestic market for knowledge intensive activities is growing rapidly, policy makers should explore if tinkering with IP policies can facilitate the participation of local firms in this market, including through incremental innovations. Consequently, assessment of specific aspects of any IP legislation should be undertaken through this lens.

Admittedly, building of scientific and technical manpower and institutions would help build Indian entities in participate in global networks. Therefore, policies that build such capacities complement IP policies that create potential for such participation.

\section{Drug Discovery Technologies and Emerging Opportunities in the Pharma- Biotech Sectors}

The innovation system in the pharmaceutical industry is very complex. The complexity of $R \& D$, which is essentially science based, has been on the rise due to the emerging synergies in the research streams of conventional chemistry, biotechnology and information technology (IT). It is becoming increasingly important to integrate knowledge at various levels of research in biomedical sciences, pharmaceuticals and IT. Institutional factors are very important for such integration and coordination. For example, institutional coordination across disciplines between academic research labs, public sector research establishments, private industrial research units, pharmaceutical firms, CROs and hospitals will be critical for such integration to take place.

Riding on the synergies between different disciplines, the drug discovery and commercialization processes are undergoing significant change. The following developments are particularly important to understand the potential changes in the 
innovation system of the pharmaceutical industry (see Economist 1998 and Jungmittag et al, 2000 for details):

- The shift from wet chemistry to bio-technology based processes for identifying/ developing a molecule or compound has reduced the economies of scale;

- Combinatorial chemistry has helped develop gene libraries that can be hired for screening resulting in significant reduction in the entry barriers in initial screening business;

- Computer aided development of molecular designs is used to filter molecules and compounds for testing with wet chemistry. This biotechnology-software interface has meant higher success rates and speedier selection of compounds;

- Actual drugs are being designed with the help of computers. Software are used to reduce uncertainty in drug development;

- New technologies in pre-clinical development are reducing the drug development cycle. For example, cassette dosing and simultaneous optimization of toxicity, bioavailability and pharmacokinetics has reduced the time required for clinical trials. Service firms have emerged to do such trials;

- Computerized safety and efficacy trials conducted on patients avoid useless regimes to reduce number and size of trials. This saves time and money. These new technologies have also facilitated the emergence of contract research organization (CROs).

Overall, these technological developments have created a situation where drug discovery and development may no more be dominated by large vertically integrated enterprises. Decline in entry barriers in several segments can lead to disintegration and decentralization of this process. Given good access to software, biotechnology and wet chemistry based skills, many firms in India are well placed to occupy several spaces in this value chain e.g., molecule identification and other niches for clinical research. However, a favourable IPR regime and good implementation of the IP laws may be essential for these firms to participate in decentralized drug discovery \& development process where several firms perform highly specialized 
tasks. This would be particularly so if the entry into these niches is innovation based or if it involves use of protected technologies. Indian firms will also need to identify their niches and create appropriate capabilities for occupying these niches. A favourable IPR regime combined with the above mentioned technological developments and the associated uncertainties might also lead to creation of networks and alliances between firms having diverse capabilities on the one hand and educational institutions \& public sector entities on the other. Through such alliances the synergies across capabilities in wet chemistry, biotechnology and IT may be reaped.

\section{Emerging Strategies of Pharmaceutical Firms}

Given the opportunities provided by the changes in drug discovery technologies, the strategies that the MNCs would adopt in countries like India will depend on a variety of factors, including the availability of skills and capabilities as well as the nature of regulation (including of IPRs) and competition in the host countries. A proactive regulatory structure can, in fact, facilitate the exploitation of these strategic opportunities by MNCs as well as the Indian pharmaceutical, biotechnology and IT companies. An appropriate IP regime, for example, may not only help exploit the opportunities created by the changes in drug development technology and the emerging structure of the pharmaceutical and biotechnology sectors but also help respond effectively to the emerging $R \& D$ and production strategies of the MNCs. Significant capabilities may get built if India becomes a hub for $R \& D$ and manufacturing related sub-contracting in this sector. While a systematic exploration of these strategies and their linkages with regulation and the innovation system would be very useful, only a preliminary exploration of these strategies is attempted below.

\subsection{MNC Strategies}

Changes in the drug discovery processes and the emerging liberal policy environment are likely to modify MNC strategies in three broad ways: 
- FDI in overseas manufacturing may increase with special focus on contract manufacturing of drugs (even the ones that are still on patent);

- More and more pharmaceutical firms may locate part of their R\&D activities in India through $\mathrm{R} \& \mathrm{D}$ centres or through outsourcing of technological activities including clinical trials; and

- The research portfolio of MNCs may shift (at least marginally) in favour of diseases relevant for the developing countries, especially those that have large populations with reasonable ability to pay. Such a shift would require specialized skills of firms, individuals and R\&D institutions in developing countries like India.

Studies have shown that many of these strategies are already been used. ${ }^{6}$ Foreign investments in the pharmaceutical and biotech industries in India have increased in recent years. Most of them are Greenfield projects and a significant proportion had R\&D focus. 7 Recent years have also seen significant increase in the outsourcing of any development processes in India by MNCs in the pharmaceutical industry. Table 1 provides information on the activity profile of Indian CROs. A large proportion of these firms are engaged in clinical development (Phase II and Phase III trials are outsourced the most), site management and clinical data management. While bio-statistics is a growing segment, with the growth of clinical trials medical writing has also picked up in India. Besides, FDA regulation filings are also being off-shored (Zinnov, 2006). Table 2 shows that all the major MNCs are outsourcing a variety of activities to India ranging from contract manufacturing to IT services, drug discovery and clinical development; contract manufacturing being most common with almost all reporting pharmaceutical MNCs reporting this activity. According to some estimates, manufacturing costs in India are about $60 \%$ of costs in western nations while drug discovery costs can be as low as $10 \%$ of their costs. There seems to be significant potential for BPO activity of this space.

\footnotetext{
${ }^{6}$ See for examples, Goldar et al (2010), Rai (2008), Linton and Corrodo (2008), Sampath (2008), Greene (2007), IVCJ (2006) and, Banerji and Bhatia (2004).

${ }^{7}$ As many as 59 per cent projects had R\&D focus during 2002-06. See Linton and Corrado (2008) for some estimates.
} 
Despite the surge in outsourcing activity in the pharmaceutical industry, several MNCs consider inadequate IP protection in India to be an important constraint on their activities. ${ }^{8}$ Some firms like Novartis claim that their decision to have research centres in Singapore and Chine and not in India was primarily due to inadequate IP protection. This is also why Novartis's collaborations in India are limited to 'supportive' (as against critical) work (Linton and Corrado, 2008:6). Interestingly, Novartis seems to be an exception and a significant number of sophisticated $R \& D$ projects have been outsourced to Indian firms or are being done in India by MNC subsidiaries. ${ }^{9}$ Moreover, MNC firm responses may be influenced by the 'official' position of the MNC association and may not reflect the true influence of IP regimes. Rai (2009) shows through survey data that many MNCs consider other factors to be significantly more important than IPRs but the responses are typically guarded. Thus, IPR related constraints may not be significant and if so, they may not be binding as other advantages of India's location overcome these constraints. Alternatively, other legal mechanisms, combined with pre-contract due diligence, and information security management systems may be adequate to ensure protection of sensitive $R \& D$ and other data. We shall revert to this issue later.

\subsection{Indian Firms' Strategic Options \& Capabilities}

Rai (2008) and Sampath (2008) provide a very useful account of strategies followed by Indian pharmaceutical firms to deal with TRIPS related challenges. Their detailed evidence shows that Indian firms have adopted a mix of competitive and collaborative business and technology strategies. There is also evidence to show that the R\&D intensity of Indian firms has increased significantly in recent years from about $1 \%$ to $6 \%$ of sales (Goldar et al 2010). An insightful econometric exercise has also shown that the impact of the strong IP regime on $R \& D$ expenditure of Indian pharmaceutical firms remains significant even after factoring in the role of other factors that may potentially affect $R \& D$ intensity. The study goes

\footnotetext{
${ }^{8}$ According to some surveys more than 62 per cent MNCs in India consider lack of IP protection the most important business risk and 63 per cent believe that integration with local suppliers and service provided may result to loss of IP. (For details, see Linton and Corrado, 2008: 3-8). Also see Rai (2009) for similar evidence.

${ }^{9}$ Linton and Corrado (2008) provide some examples.
} 
on to show that Indian firms have increased their patent filings both in India and abroad and that increased $R \& D$ expenditures have had a significant and positive impact on domestic and international patent filings of Indian firms (Goldar et al, 2010: 129-39). In other words, a shift to a stronger IP regime has not only resulted in higher $R \& D$ intensity but the domestic firms have increased patenting in India and abroad.

Figures 1 and 2 provide estimates of US patenting by Indian pharmaceutical and biotech firms and the composition of these patents. Interestingly, while few (less than 15 per cent) firms patent, $48-59$ per cent of those Indian firms that patent in the US have product claims. Similarly, according to the Patent Cooperation Treaty (PCT) database, Indian companies have filed approximately 4200 applications. Of these applications 55 per cent are for pharmaceutical incremental innovations. For instance, Ranbaxy has filed 239 patent applications of which 122 are for derivatives, formulations, compositions and new dosage forms. Most of Ranbaxy patent applications are for incremental innovations. In general, Apart from new chemical entities (NCE), the focus on new use patents seems to be on the rise. (Sundaramoorthy et. al., 2009).

Unfortunately, similar categorization is not readily available for patents filed in India by domestic companies and we cannot ascertain the nature of inventions that are being protected and if these are different from the type of inventions being protected in the USPTO. But it is broadly argued that during the pre-TRIPS period, the Indian pharma industry developed unique skills in chemistry and biochemistry. Now, Indian companies can compete effectively with global majors in developing new salts, new derivatives, new uses, new dosages and new delivery systems. Besides, different domestic firms seem to be following differential patenting strategies vis-à-vis foreign and Indian filings. For example, unlike Ranbaxy which files large proportion of their applications abroad, Dr Reddy's Laboratories, Orchid Chemicals, Cadilla Healthcare, Cipla and Sun Pharmaceutical Industries file majority of their applications in India (James, 2009). 
Preliminary explorations suggest that pharmaceutical firms in India are exploring a variety of strategic options (Table 3$)^{10}$. In what follows we discuss some of them briefly.

a. Develop new pharmaceutical products. So far, the trend is that firms find new chemical entities, patent them in major international markets develop them up to a point and then license them to MNCs for further developments and clinical trials. This grow and sell strategy followed by a few firms exploits relatively inexpensive research skills and transfers costs of trials but shares some risks of drug discovery.

Apparently, the licensing arrangements are proliferating because the costs of taking an invention from conception to market are escalating. At each stage, the costs and risks increase exponentially and so it make sense for Indian firms, who have limited resources but an abundance of low-cost and highly trained scientists, to focus on basic results and license the results. Very few firms may, however, have the product development and licensing skills and capabilities to implement this strategy. Exploitation of relatively inexpensive research skills and process capabilities that have been acquired over the years may be more feasible, if a firms wishes to opt for an R\&D intensive strategy. The other strategies to exploit emerging niches in drug discovery, drug delivery, process innovations etc.(see below) may be more relevant for relatively smaller enterprises.

b. Undertake outsourced $R \& D$ activity for early stages of the new drug development This strategy also exploits relatively inexpensive research skills but do not share risks. Few firms are engaged in this now but the activity is growing.

\footnotetext{
${ }^{10}$ Goldar et al (2010), Rai (2008a), Basant (2005) and Banerji and Bhatia (2004) also provide examples of firms that are adopting these strategies. Athreye, Kale and Ramani (2008) provide details of strategies followed by large domestic pharmaceutical firms in India. Similar evidence is available in Rai (2008a) and Goldar et al (2010: 118). Almost all these firms adopt a combination of these strategies.
} 
c. Focus R\&D on drug delivery mechanisms, dosage forms and bio-enhancers to improve the efficacy of existing patented drugs

This strategy exploits existing drug delivery related R\&D skills and process capabilities. Once this is achieved, cross licensing possibilities with the patent holder of the drugs that are affected by these inventions can be explored ${ }^{11}$. Many process patents filed by Indian firms in the US cover new drug delivery technologies (Sundarmoorthy et.al., 2009).

d. Focus on process $R \& D$ (optimization) for patented drugs to acquire process patents and explore cross-licensing/ licensing options. ${ }^{12}$

These process inventions are also very useful for quick entry once the drug gets off patent and can also facilitate linkages with $\mathrm{MNCs}^{13}$.

e. Bio-informatics based sub-contracting and other clinical research (CROs). The data on this is quite limited but the activity seems to be growing.

f. Build alliances with biotech and IT firms and also with educational institutions to develop new technologies for pharmaceutical research. IT firms are also gradually entering into the health domain. These research based opportunities have multiplied with the growth of biotechnology in India. ${ }^{14}$ With technological change,

\footnotetext{
${ }^{11}$ This strategy can also be useful for off-patent drugs. Bayer patented ciprofloxacin in 1983 and its patent expired in 2003. As such others were free to research and study the molecule. The research by Ranbaxy led to the development of a once-a-day oral dosage form, which increases patient compliance and convenience. Bayer bought the product development and global marketing rights from Ranbaxy for a fee of over \$65 million. Ranbaxy will also receive up to 10 per cent royalties on sales.

${ }^{12}$ Matrix Laboratories developed a non-infringing process for the blockbuster anti-depressant, the $\$ 1.5$-billion Citalopram. Lundbeck, a Danish pharma company and the Originator, made a \$40-million offer - nearly half of Matrix's annual revenues - for this manufacturing process.

${ }^{13}$ Hyderabad-based Avon Organics developed the biotechnology process for pseudoephedrine (an off-patent raw material cold formulations and syrups) and its derivatives, with GlaxoSmithKline (GSK). Ever since Avon changed its strategy from a general API (active pharmaceutical ingredient) supplier to a friendly API supplier in 1996, its revenues have grown from Rs. 16 crore to Rs. 90 crore today.

${ }^{14}$ According to some estimates, there are about 800 biotech related companies, with 96 firms exclusively working with biotechnology. With beginnings in fermentation and enzyme production, the industry has now grown to about \$1.07billion and covers new drug discovery, bio-informatics, clinical research and synthetic chemistry. About 230 biotech-based drugs are already in the market covering 13 therapeutic segments (IVCJ, 2006; 28). Moreover, genomic research, bio-generics and stem cell research are adding fresh opportunities for growth.
} 
several new opportunities for IT firms to work on the boundaries of other sectors like the pharmaceutical and biotechnology are becoming available. It is becoming increasingly important to integrate knowledge at various levels of research in biomedical sciences, pharmaceuticals, and IT. Riding on the synergies between different disciplines, the drug discovery and commercialization processes are undergoing significant change. Based on the changes in the drug discovery systems discussed earlier, several opportunities seem promising. Increasing use of combinatorial chemistry to develop gene libraries that can be hired for IT based screening will result in significant reduction in the entry barriers in initial screening business. Besides, computer aided drug design, use of IT in pre-clinical trials and computerized safety and efficacy trials also provided new entrepreneurial opportunities. All these domains are very IP intensive and would require a more proactive participation of Indian firms in IP protection. This will obviously lead to enhanced participation of these firms in IP generation and creation. There is evidence to show that Indian IT firms are increasingly exploiting these domains as well. ${ }^{15}$

g. Focus on contract manufacturing of patented drugs. Adoption of good manufacturing practices (GMP) facilitates this strategy. That the scope for contract manufacturing is high can be gauged by the fact that India has more than 85 FDA approved drug manufacturing plants and over 200 Good Manufacturing (GMP) compliant manufacturing plants (Linton and Corrado, 2008; IVCJ, 2006).

h. Focus on drugs, which are going to be off patent in the near future. This strategy is very dominant and is particularly being followed to enter developed country markets as soon as the relevant patent expires.

\footnotetext{
${ }^{15}$ Strand Genomics, a spin out firm from a well-known institute of science education (Indian Institute of Science, Bangalore) is a prime example of this trend. Other firms active in this domain include Agilent Technologies (Life Sciences and Chemical Analysis), Wipro Health Science, SysArris Software and Kshema Technologies.
} 
i. Produce drugs that are off patent today. Most of the firms are doing this in India.

j. Combine some of these strategies with co-marketing/marketing arrangements. Marketing and distribution assets can be gainfully used through this strategy.

It is evident that the IP regime and its implementation will affect most of these strategies. This will be particularly the case with respect to product patenting, data exclusivity etc. A relevant question is whether these strategies are influenced only by the Indian IP regime or also on IP regimes elsewhere, especially in western markets. All these strategies can be followed by patenting innovations (incremental as well as others) in India as well as in those economies where the market is large for domestic firms. We will come back to this issue later.

\section{Emerging Opportunities, Firm Strategies and IPR Regimes}

Having laid out the heuristics, emerging opportunities and strategies of firms in the pharma-biotech sector, we now focus on the current IP policy debates in India and explore if a more analytical view can be taken on the emerging IPR needs of this sector in the Indian economy. The Indian state introduced a TRIPS compatible IPR regime in 2005 by permitting product patents in all sectors including pharmabiotech and food where only process patents were allowed earlier. Instead of focusing on all aspects of the new IP regime in India, we focus on two very contentious issues relating to the biotech-pharma sector. These relate to the protection of incremental innovations and data. The issue of incremental inventions in the sector has been discussed around the patentability of new uses of existing chemical entities, new drug delivery mechanisms and dosage forms. Data protection concerns are related to clinical trials data also referred to as data exclusivity. In what follows, we review these issues in the context of changes in technology and industrial structures discussed above and in view of recent changes in IPR regimes elsewhere. 


\subsection{Protecting Incremental Innovations}

Among others, the following are excluded from patentability in the new patent law in India. These have significant implications for the pharmaceuticals and the biotechnology industries:

1. A mere discovery of any new property or mere new use for a known substance or of the mere use of a known process, machine or apparatus unless such known process results in a new product or employs at least one new reactant;

2. A mere discovery of a new form of a known substance, which does not result in the enhancement of the known efficacy of that substance;

3. A process for the medicinal or other treatment of human beings and animals.

These patentability conditions combined with the explanation of Article 3 (d) which sets out the first two conditions ${ }^{16}$, initially gave the impression that the Indian law does not permit incremental innovations as it does not allow patents for new uses $\&$ therapeutic methods patents and seem to put significant constraints on the patentability of new dosage forms \& drug delivery mechanisms. Subsequent discussions, however have questioned this interpretation.

We saw in the earlier section that very few Indian firms are actually engaged in the discovery of new chemical entities; most are engaged in incremental inventions. Such a research strategy makes sense as the $R \& D$ costs of the pharmaceutical industry are on the rise. The development of this research strategy has been largely attributed to factors like increase in number of known pharmaceutical compounds over the years, knowledge of their toxicological profile and increase of standard of life sciences in the last four decades. Besides being cost-efficient and time saving, such new uses are easier to obtain regulatory approval than conventional new molecular entities. And this is a worldwide phenomenon; during 1989-2000, only

\footnotetext{
${ }^{16}$ The explanation states that 'for the purposes of this clause, salts, esters, ethers, polymorphs, metabolites, pure form, particle size, isomers, mixtures of isomers, complexes, combinations and other derivatives of known substances shall be considered to be the same substance, unless they differ significantly in properties with regard to efficacy.
} 
35\% [361] of all the drugs [1,035] approved by the Food and Drugs Administration in the United States consisted new molecular entities or drugs consisting new active ingredients (NIHCM, 2002). The remaining 65\% of drugs contained active ingredients that were already available in marketed products. Out of these, 558 drugs differed from the marketed product in dosage form, route of administration, or were combined with another active ingredient. ${ }^{17}$ Given these trends, the US and Europe have provided scope to protect such investments through patents. ${ }^{18}$

It has been argued that by making derivates with added efficacy patentable, section 3(d) encourages sequential incremental innovations of existing products or technologies that may help commercialization of improved products (Basheer and Reddy, 2008). Interestingly, a study supported by MNCs has argued that article 3(d) discriminates against incremental innovations and therefore many Indian firms who can potentially benefit from protection of such inventions would suffer due to this clause. To buttress their argument, data on patent applications on incremental innovations filed by Indian firms in foreign countries is cited to argue that such innovations are 'potentially precluded from patent protection in India because of Section 3(d)' (US-India Business Council and Coalition for Healthy India, 2009: 16) . In contrast, those in favour of Article 3(d) provide data on patents granted after 2005 to foreign firms in India which show that these are not only for 'breakthrough drugs' but for 'minor variations of existing pharmaceutical products' as well (James, 2009: 13). And these patents have included new molecules and processes as well as new uses, combinations and dosage forms.

Moreover, Section 54 of the Indian Patent Act provides for 'patent of addition' which adds on new uses and improvements to the original patented invention but this patent of addition expires with the original patent (James, 2009: 25). Consequently, the emerging interpretation of the Indian IPR regime (especially Section 3(d)) is that it permits patenting of incremental innovations of all types discussed above but

\footnotetext{
${ }^{17}$ See US-India Business Council and Coalition for Healthy India (2009), for similar evidence.

${ }^{18}$ The nature and level of protection for such interventions, is however, different in the two countries. (See Appendix I).
} 
only those which have significantly higher efficacy to avoid trivial changes to avoid 'ever-greening'. ${ }^{19}$ The key issue then is as to how the enhancement of efficacy would be measured and its scope decided. In a recent case filed by Novartis regarding the patentability of Glivec, an anti-cancer drug, the Madras High Court has suggested that efficacy enhancement should be looked at through the lens of therapeutic efficacy. Basheer and Reddy (2008) provide an excellent summary of the issues around defining efficacy. It is argued that the definition of efficacy should not be restricted to 'therapeutic efficacy' alone but should include bio-availability, stability, and safety. Moreover, a very high threshold of efficacy might harm the interests of many domestic producers. 20 One recommendation is to use the doctrine of "unexpected or surprising results" to determine patentability of pharmaceutical derivatives as is done in the US as it includes not only therapeutic efficacy but other significant advantages like enhanced bio-availability, heat stability, humidity resistance etc. (Basheer and Reddy, 2008). Some others believe that this may not be an appropriate solution as recent court decisions in the US suggest that applications may get rejected for obviousness, even when supported by unexpected results (James, 2009). The issue gets further confounded when different stakeholders attribute different value to various features of the drug with the views of doctors, pharmacists and patients not coinciding with each other (see Table 4). One can see that different types of 'efficacious' outcomes are preferred by these stakeholders.

Overall then, the Indian IP regime seems to be adequate to provide protection to a large variety of incremental innovations including new use, drug delivery systems and dosage forms. Once the issue of efficacy gets sorted out the remaining regulatory uncertainty would also get taken care of. But it may be useful to start with higher 'thresholds' as the developed country market seem to be more

\footnotetext{
${ }^{19}$ Analytically it may be useful to find out if the inventions for which Indian firms have filed patent applications abroad can qualify for a patent in India. It is likely that applications for the same have also been filed in India. In the same vein, one needs to ascertain how many patents for 'incremental innovations' of foreign firms did not get a patent in India but were provided such a protection elsewhere. Such analyses, unfortunately is not available. ${ }^{20}$ See Basheer and Reddy (2008) for examples wherein inventions of Indian firms under restrictive efficacy standard may not qualify for protection.
} 
important for large firms in India than the domestic market. Therefore, most incremental inventions may in any case get protection in western markets and aid strategies of Indian firms in these economies. The Indian firms' strategic options may not get constrained by the high thresholds in India. Besides, even in the absence of a product patent regime in India, domestic pharmaceutical firms would have focused on incremental inventions (and patent them in developed countries) as it is critical for them to move up the value chain in the international markets. The strategic options discussed in Rai (2008) and Goldar et al (2010) suggest that such a focus is important to penetrate global markets especially the USA. However, if high thresholds in the domestic context limit participation of Indian firms in global innovation/production markets, one may need to reconsider this issue. As of now, the available data seems to suggest that such regulatory uncertainty is not a significant constraint.

The task of finding the 'optimal' novelty or efficacy standards is a difficult one and is likely to evolve only through corporate and juridical experience. While we gain that experience it may be useful to also consider the option of petty patents. Studies of IP systems in Japan and elsewhere have shown that certain features of their systems facilitated technology diffusion (Maskus and McDaniel, 1999). The primary channel of technology diffusion in Japan was derived from applications for utility "models, which are incremental inventions that build on knowledge in existing patent applications and that can be put to commercial use quickly. (The U.S. patent system offers no equivalent to the utility model.) Japanese and foreign patents were used as the bases for modified technologies. The industries that most often built upon foreign patent applications and filed domestic utility model applications were in chemistry (including metallurgy) and the physics, communication, and measurement industries. One important indirect result of initial patent applications was the stimulation of follow-on utility models. All this encouraged diffusion that promoted "catching up" to advanced technologies. The 1994 amendments to Japan's intellectual property laws streamlined the utility model application process by eliminating the examination (effectively ending the need for publication of the application and opposition procedures) and shortening 
the length of protection from 15 years to 6 years from the application filing date. The shortened term of protection, coupled with increased registration and maintenance fees, reduced the expected value of a utility model and thus caused a decrease in the number of utility applications in favor of patent applications (Aoki, 1997). For Indian firms such an option may still be useful. It can be argued that the Indian Patent Office has limited resources and such a system would put pressure on them. There will be some additional burden but it may be desirable because such patents would enhance the utility of the pre-grant disclosure and opposition provisions that the Indian Act has included. Now, the local firms would look at these applications not only from the perspective of opposition but for incremental innovations. Similar provisions in Japan and South Korea resulted in significant cross licensing between original and the subsequent (incremental) innovators. This in turn facilitated learning and diffusion of patented technologies. The utility of this provision would get enhanced if the claims are narrowly defined, a feature all patent systems should work towards. ${ }^{21 B e s i d e s, ~ t h e ~ d u r a t i o n ~ o f ~ p r o t e c t i o n ~ t h r o u g h ~ s u c h ~}$ patents would be lower.

Admittedly, MNCs are on the forefront in undertaking incremental inventions. The regulatory environment in the US and Europe seem to have facilitated such an innovation strategy. Any regulatory regime that facilitates protection of such inventions would help the MNCs more than the Indian firms. But this strategy appears to be cost-efficient and less risk-prone, and slowly Indian pharmaceutical companies seem to be getting into this strategy and therefore may gain from grant of patents for incremental inventions, including the grant of petty patents. It is not known if such a strategy would become more common or if Indian firms would be able to compete with MNCs.

\subsection{Issues Relating to Data Exclusivity}

The data protection relates to the information collected during clinical trials to get marketing approval. Since collection of such data is expensive, most countries

\footnotetext{
${ }^{21}$ Koneru (1998) makes a very strong case for narrow claims to facilitate innovation and diffusion.
} 
distinguish between protection of these data and the patent protection for the drug for which the trials are being undertaken. If the authorities use these data to test the bio-equivalence of generic drugs, the cost and time requirements for the manufacturers of generics decline dramatically. Consequently, it is argued that data protection can delay the entry of generics and adversely affect consumers due to higher prices. TRIPS agreement requires that the member countries protect data from 'unfair commercial use'. It is not clear what this implies and many suggest that it does not necessarily require data protection. In any case if the data is not shared by the regulatory agency with the generics competitor but used only for assessing applications for generics, many believe it should not tantamount to 'unfair commercial use'. Several issues have remained unresolved despite a lot of discussion on this issue. These include:

1. What drugs are eligible for data protection? Only those which are patented or also those which are newly registered. Should such protection be restricted to only new chemical entities (NCE) or all new dosage forms, drug delivery systems etc.

2. When should the data protection period begin? It can coincide with the patent term or start with the date of the marketing approval or the first commercial sale. Should the marketing approval/sale be specific to a nation or approval/sale anywhere in the world should stat the clock.

It is obvious that the choices on the above set of questions would determine the duration of protection. Defining scope, period and unfair use is therefore important. While data protection is desirable, identifying the best option from the above is not easy but the following are useful to consider:

- If data exclusivity results in a situation that the domestic generics manufacturer gets delayed in entering the generics market while competitors elsewhere in the world, it would constrain the manufacture from entering the global production networks. 
- Applications for generic dug approvals during the period of data exclusivity would facilitate faster entry by domestic players even though the regulatory authority may not use the available data during this period.

- If efficacy requirements are high, most new drug delivery mechanisms can only be protected through data exclusivity as trials data is required before market approval. Non-availability of such protection may be biased against those who focus on such incremental innovations.

The Indian Patent Act has rightly incorporated the "Bolar" Provision, that effectively allows manufacturers to begin the research and development process in time to ensure that affordable equivalent generic medicines can be brought to market immediately upon the expiry of the originator product's patent. The efficacy of this provision is dependent on early availability of clinical trials data. Data exclusivity rules, therefore, should not be stringent. Duration of data exclusivity should be amended to allow the effective scope of patent protection to be limited to 20 years. MNCs and some Indian associations of pharmaceutical companies (OPPI) have sought amendments to the Drugs and Cosmetics Act to include a provision of Data Exclusivity for a period of five years from the date of marketing approval. Data Exclusivity on research data provided in order to secure marketing rights on pharmaceuticals is considered important by these players as it takes up to 10 years of time and investment to generate such data, which provides an important competitive advantage. Having no data exclusivity may not be TRIPS compatible but a shorter period of data exclusivity at this point of time would be desirable for the Indian firms. Short periods of exclusivity would also enhance the utility of the Bolar provision. However, such a change falls outside the purview of the Patent Act.

Given all these considerations, the Indian law seems to be by and large appropriate as it protects test data for pharmaceutical drugs as a trade secret under common law. The regulator who evaluates safety and efficacy of drugs can, therefore, refer to the clinical data to approve generic versions of drugs. (Goldar et al 2010), It has been argued that lack of data protection would constrain the use of CROs by MNCs. Besides, low rank of India in overseas funding by the National Institute of Health 
(NIH) as compared to China (rank 9 vs. rank 2) is attributed to lack of data protection in India (OPPI, 2008). This argument is not convincing as data generated by trials outsourced to India is not even shared with the Drug Controller General of India. Moreover, as mentioned earlier, trials data can be adequately protected through a variety of other legal mechanisms like Official Secrets Act and Common Law. Thus, data protection is unlikely to be a key constraint on FDI. However, it is not entirely clear if Indian firms would require data protection to protect their incremental inventions in the presence of high efficacy standards as these inventions would not be patentable. So long as the market for these inventions is in the western world, such contingencies would not arise but if these incremental inventions are for the domestic markets, the policy choice becomes somewhat difficult.

\section{In Lieu of a Conclusion}

The IP regimes typically have to deal with a trade-off between invention and diffusion of technologies. Very stringent IP regimes can reduce the opportunities for building on existing technologies. This paper summarised the available evidence on recent changes in the technology and industrial structure in the global pharmaceutical-biotech industries to understand the emerging trends. An exercise was then done to ascertain how the opportunities for Indian firms have changed due to these global changes. The final question was to assess if the existing IPR policies in India can potentially constrain the exploitation of these emerging opportunities by Indian firms. If yes, what changes are desirable? A review of the emerging IP regime in India suggests that a sharper focus on incremental innovations and data protection on the lines discussed above seems desirable as it would reduce regulatory uncertainty and firm up opportunities for Indian firms to participate in networks to build capabilities. More specifically, patentability of incremental innovations (e.g., novel new uses of existing compounds and inventive NDDS) is desirable but significant lowering of novelty and efficacy thresholds is not immediately required. The utility of the current regime on data exclusivity, however, is somewhat more difficult to assess. The current policy seems adequate to exploit the opportunities provided by the Bolar provision in the new Patent Act. But its 
usefulness to protect incremental inventions that are not patentable due to high efficacy standards and are meant for the domestic market still needs to be explored. One would require more detailed data on the focus of Indian firms' incremental inventions to take a call on this issue.

Finally, it is useful to briefly discuss the role of other policies that might work in conjunction with the IP policies, an issue that was raised in the introduction and as a part of the heuristic framework. It is well-known fact that effectiveness of IP regimes is often dependent on other complementary regulatory arrangements. For example, policies that permit anti-competitive behaviour based on IP based monopolies can inhibit licensing and cross-licensing arrangements reducing the potential of technology diffusion. The debate on the Microsoft case in the US provides ample evidence on the relevance of such linkages. In the Indian debate the burden of controlling pharmaceutical prices is usually put on the IP regime. This is not advisable. Compulsory licensing is an important mechanism available under TRIPS to curb misuse of IP protection which most developing countries have rightly used. Some modifications in the compulsory licensing regime of India may help use the anti-competitive clause. According to the current IP laws in India, at any time after the expiration of $\mathbf{3}$ years from the date of sealing of a patent, any interested person can make an application to the Controller for a Compulsory License on any of the following grounds:

- Reasonable requirements of the public with respect to the patented invention have not been satisfied.

- The patented invention is not available to the public at a reasonably affordable price.

- The patented invention is not worked in the territory of India.

While the first clause makes sense, the other two can be problematic. It is not clear if the last clause is TRIPS compatible. Using a price criterion to evaluate an IP regime while Drug Price Control Order is TRIPS compatible seems superfluous and 
makes the interpretation of "reasonably affordable price' quite cumbersome. Surprisingly, the provisions on compulsory licensing deem specific instances of anti-competitive behavior as not satisfying "reasonable requirements of public". A new clause needs to be added to broaden the scope of the first condition. This is particularly desirable because according to TRIPS, compulsory licensing undertaken due to anti-competitive practices need not have any restriction on the export of the patented product.

We have argued elsewhere that high pharmaceutical prices in Pakistan vis-à-vis India are not attributable to differences in IP regimes; Indian FDI and industrial policy combined to build capabilities among the Indian pharmaceutical firms and reduced the monopoly power of MNCs (Basant, 2007). Combinations of such policies need to be explored continuously to leverage the benefits of IP regimes. The current IP regime is unlikely to influence the nature and quantum of FDI in the pharma-biotech industry but lack of infrastructure and limited drug discovery skills ${ }^{22}$ may perform that function. A policy focus on that is desirable in order to facilitate the participation of Indian firms in global production and innovation networks and consequently build capabilities. We reiterate that the ability to encourage such participation should be the key lens through which IP regimes and the complementary policies should be assessed in countries like India where initial capability requirements to participate in such networks already exist.

\footnotetext{
${ }^{22}$ See Saberwal (2008) for some discussion on the skill gaps that are emerging in drug discovery in India.
} 


\begin{tabular}{|l|l|}
\hline \multicolumn{2}{|c|}{ Table 1: Activity Profile of CROs in India } \\
\hline Service Category & $\begin{array}{l}\text { Percent of CROs engaged in the } \\
\text { service }\end{array}$ \\
\hline Drug discovery & 18 \\
\hline Pre-clinical development & 23 \\
\hline Clinical development & 77 \\
\hline Clinical data management & 55 \\
\hline Site management & 64 \\
\hline All & $100(22)$ \\
\hline
\end{tabular}

Note: Estimate based on service offerings of the 22 leading CROs in India.

Source: Zinnov Pharmaceutical Outsourcing Landscape in India, 2006.

\begin{tabular}{|c|c|c|c|c|c|c|c|}
\hline \multicolumn{8}{|c|}{ Table 2 : Nature of Outsourcing by Major Pharmaceutical Multinationals in India } \\
\hline \multirow[b]{2}{*}{ Company } & \multicolumn{3}{|c|}{ IT Services } & \multirow[b]{2}{*}{$D D$} & \multicolumn{3}{|c|}{ Development } \\
\hline & $C M$ & $I T-A D$ & $I T-I S$ & & $C T$ & $C D M$ & $S M$ \\
\hline GSK & $\mathrm{X}$ & $\mathrm{X}$ & $\mathrm{X}$ & $\mathrm{X}$ & $\mathrm{X}$ & $\mathrm{X}$ & $\mathrm{X}$ \\
\hline Aventis & & & $\mathrm{X}$ & $\mathrm{X}$ & $\mathrm{X}$ & & $\mathrm{X}$ \\
\hline Pfizer & $\mathrm{X}$ & & $\mathrm{X}$ & $\mathrm{X}$ & $\mathrm{X}$ & $\mathrm{X}$ & $\mathrm{X}$ \\
\hline Novartis & $\mathrm{X}$ & & & & $X$ & & $\mathrm{X}$ \\
\hline $\begin{array}{l}\text { Astra } \\
\text { Zeneca }\end{array}$ & & $\mathrm{X}$ & $\mathrm{X}$ & & $\mathrm{X}$ & & $\mathrm{X}$ \\
\hline Eli Lilly & $\mathrm{X}$ & & & $\mathrm{X}$ & $\mathrm{X}$ & & $\mathrm{X}$ \\
\hline Merck & $\mathrm{X}$ & & & & & & \\
\hline BMS & $\mathrm{X}$ & & & & & & \\
\hline Roche & & & & & & & \\
\hline Wyeth & $\mathrm{X}$ & $X$ & & $\mathrm{X}$ & & $\mathrm{X}$ & \\
\hline
\end{tabular}

Source: Zinnov - Pharmaceutical Outsourcing Landscape in India, 2006.

Note: CM - Contract Manufacturing; IT-AD - IT Application Development; IT-IS IT Infrastructure Support; DD- Drug Discovery; CT - Clinical Trials; CDM Clinical Data Management; SM - Site Management. 


\begin{tabular}{|l|l|}
\hline \multicolumn{2}{|l|}{ Table 3: Emerging Strategies of Indian Pharmaceutical Firms } \\
\hline Strategy & Companies \\
\hline A. Supply Partner/Sourcing Base & \\
\hline $\begin{array}{l}\text { A1. API, Intermediates, Dosage } \\
\text { Forms }\end{array}$ & Cipla, Biocon, NPL, Dishman, Cadila \\
\hline $\begin{array}{l}\text { A2. Contract Research \& } \\
\text { manufacturing }\end{array}$ & \\
\hline $\begin{array}{l}\text { A21. Contract manufacturing } \\
\text { (CMO) }\end{array}$ & $\begin{array}{l}\text { Shasun, Jubilant, Dishman, Cadila, } \\
\text { Syngene }\end{array}$ \\
\hline A22. Contract Research (CRO) & Vimta labs, Clingine \\
\hline B. Generic Manufacturing & \\
\hline B1. Para II/III Generics & $\begin{array}{l}\text { Ranbaxy, Dr. Reddy's, Sun Pharma, } \\
\text { Wockhart, Cadila }\end{array}$ \\
\hline B2.Patent Challengers & Ranbaxy, Dr Reddy's, Sun Pharma \\
\hline C. Innovator & \\
\hline $\begin{array}{l}\text { C1. New Drug Delivery System } \\
\text { (NDDS) }\end{array}$ & Ranbaxy, Cipla, Sun Pharma \\
\hline $\begin{array}{l}\text { C2. New Chemical Entity (NCE) } \\
\text { Research }\end{array}$ & $\begin{array}{l}\text { Ranbaxy, Dr Reddy's, Sun Pharma, } \\
\text { Glenmark }\end{array}$ \\
\hline
\end{tabular}

Source: IVCJ (2006), p. 23

\begin{tabular}{|c|c|c|c|}
\hline Feature & M.D.s & Pharmacists & Patients \\
\hline Rapid Relief & 7 & 2 & 4 \\
\hline Ease of Use & 6 & 3 & 3 \\
\hline Facilitates Compliance & 2 & 10 & 8 \\
\hline Schedule Simplicity & 5 & 5 & 7 \\
\hline $\begin{array}{l}\text { High Effective/ } \\
\text { Superior }\end{array}$ & 3 & 4 & 1 \\
\hline Once Daily Dosing & 4 & 6 & 2 \\
\hline Safety & 1 & 1 & 6 \\
\hline Combination Product & 8 & 7 & 5 \\
\hline No addiction & 10 & 9 & 9 \\
\hline $\begin{array}{l}\text { Full Range of } \\
\text { Strengths }\end{array}$ & 9 & 8 & 10 \\
\hline
\end{tabular}

Source: Werthemeir, Radican and Jacobs (2010): 27 (Table 3) 


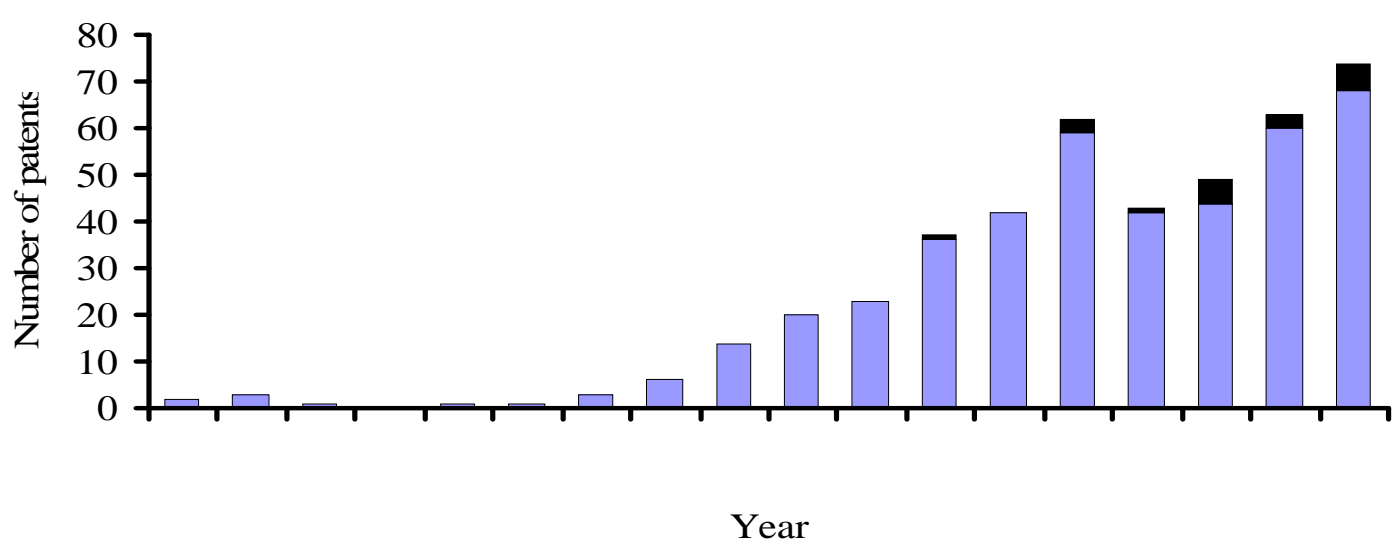

Figure 1. The growth of Indian companies' US biotech and pharma patents over the years. Note: The blue portions refer to pharma, and the dark portions to biotech patents.

Source: Sundarmoorthy et al (2009)

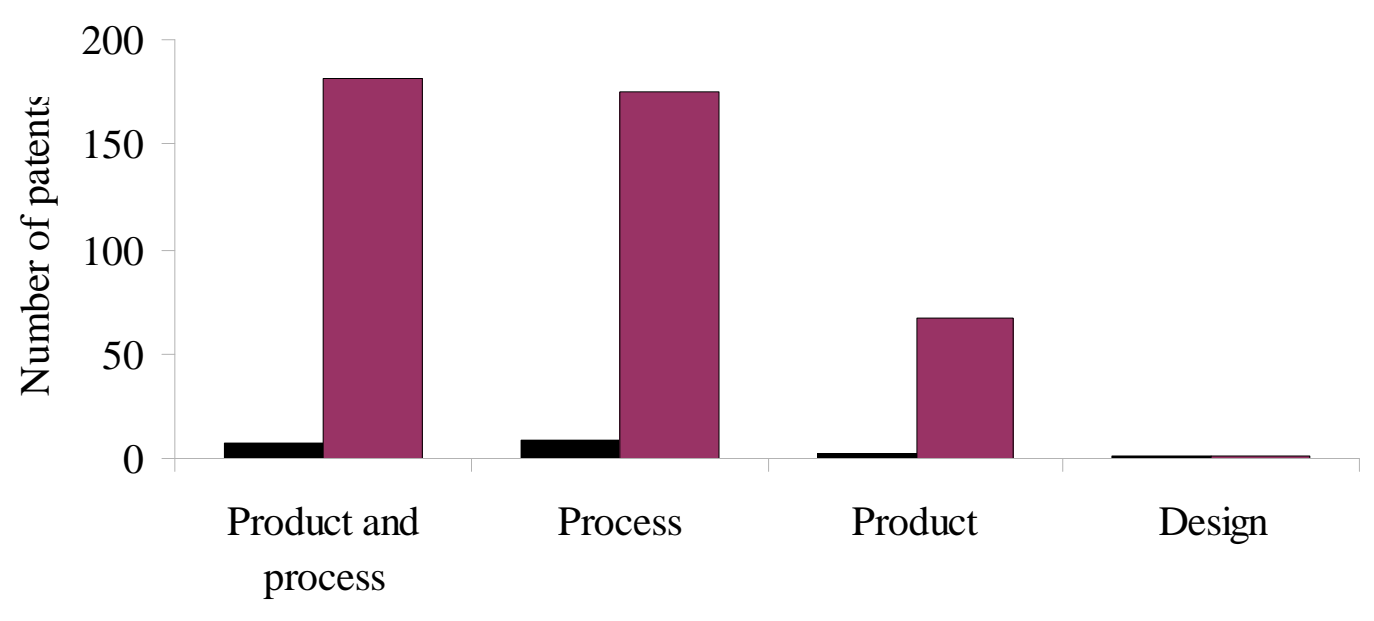

Figure 2: Categories of Patents by Indian Companies in the US

Note: Biotech patents in black) and pharma inventions in maroon.

Source: Sundarmoorthy et al (2009) 


\section{Appendix I}

\section{ISSUES RELATING TO NEW USE AND DRUG DELIVERY PATENTS The US and European Experience ${ }^{23}$}

The European Patent Office grants new use patents but makes a distinction between discovering a new use of a known substance [not known to be a pharmaceutical substance] and discovering a new use of a known pharmaceutical substance. The former is termed as first medical indication and the latter subsequent medical indication.

To the former, product patent protection is granted; the EPO treats them like any new molecular entity. Only a method/use patent is granted to subsequent medical indications. The EPO requires higher standards of utility and disclosure for granting such use patents. The EPO Guidelines state that mere pharmaceutical effect does not necessarily imply therapeutic effect. It requires the patent application to state the therapeutic application in form of a defined and real treatment of a pathological condition. The breadth of patent claims disclosing subsequent medical indications are limited to the specific new use that is disclosed in the patent application. If a patent applicant intends to include more than one new use in a patent application, the patent applicant must clearly mention each one of them in the application. New use is broadly defined. Basically, if a compound manages to treat a new disease, the EPO would consider such uses novel. Furthermore, use of the same compound for a different class of patients or a new way of administering the drug also seem patentable.

Unlike the European law, where product patent is granted to known substance for the first new medical use and use patent for any subsequent uses, the US law does not distinguish between first medical use and subsequent medical uses of a known compound. The US law permits only use/method patents for known substances on grounds of lack of novelty and non-obviousness. ${ }^{24}$ If the known substance is commercially applicable only for the purpose that is laid down in the process patent, such a known substance is regarded to be a 'non-staple article' and the patentee can bring action for contributory infringement against an alleged infringer for making and selling such a non-staple article.

Furthermore, if the patentee makes a slight change to the structure of the known substance that has a new use, product patent could be granted as long as it is nonanalogous and complies with other requirements of patentability like novelty and non-obviousness. A unique incentive is also afforded to drug companies in the

\footnotetext{
${ }^{23}$ This subsection is essentially based on Nagarsheth (2005).

${ }^{24}$ The rule that no product patent may issue for discovery of a new use for an old product or process is tempered by the 'doctrine of slight changes'. It has been commented that so long as the old product has been altered (however slightly) to fit the new use discovered by the inventor, there is no novelty bar to obtaining the patent. Furthermore, the altered product may be patented if the discovery of new use and alteration when considered together indicate 'invention', that is, non-obviousness. If the new use is merely analogous to the known product's known use, then generally the discovery will fail to meet the standard of non-obviousness.
} 
United States to incrementally innovate through the Hatch-Waxman Act. In case of branded drugs getting approved from the FDA, the modified version of the branded drug on the basis of new clinical studies, would receive three years of market exclusivity on 'the new use' of the product, beginning on the date of the approval. 'New use' in this context encompasses not only new indications but also other changes like dosage forms, method of administering the drug and incorporating a new combination drug. During these three years, no generic company can market a product that is directly competing with this new use. Thus, by modifying the same drug repeatedly, a brand manufacturer may be able to keep directly competitive generics off the market for a decade or more after the compound patent on the drug has expired. Furthermore, in cases of incremental innovation with no new use [for instance, less side effects or different mode of administering drugs], state governments who regulate pharmacy practice encourage pharmacists to prescribe new version of the old drug. Hence, it is apparent that the regulatory laws and the patent protection play an important supporting role in fostering incremental innovation within the pharmaceutical industry.

The US law clarifies that discoveries of natural and inherent chemical or biological properties per se is not a new use invention. Thus, inventions that use same compounds for treating same disease but which merely discloses a new natural or inherent biological or chemical property of the substance are not patentable. Like European law, the US law also permits patents where the new use is not in discovering treatment for a new disease, but for a new class of patients. New modes of administering a drug can also be patented. 


\section{References}

Aoki, R. 'Recent Trends in the Japanese Industrial Property System'. Presented at Intellectual property; Japan and the New Asia; Japan Information Access Project, Washington, DC, October 1997.

Athreye, S, D Kale and S V Ramani (2008), 'Experimentation with Strategy and the Evolution of Dynamic Capabilities in the Indian Pharmaceutical Sector, Mimeo.

Basant, R (2004), "U.S.-India Technology Cooperation and Capability Building: The Role of Inter-Firm Alliances in Knowledge-Based Industries", Occasional Paper, East West Centre, Honolulu, Hawaii, Economic Series, No.2, January 2004.

Basant, R (2006), "Intellectual Property Rights Regime and Creation of Innovation Based Enterprises in India". Paper presented at Globelics 2006, held at Trivandrum, India during October 4-7, 2006

Basant, R (2007), "Intellectual Property Rights Regimes: Comparison of Pharma Prices in India and Pakistan", Economic and Political Weekly, Review of Industry and Management, 42 (39), September 29 - October 05, 2007.

Basheer S. and A. Primi (2009), 'The WIPO Development Agenda: Factoring in the "Technically Proficient Developing Countries", in J. de Beer (ed.), Implementing the World Intellectual Property Organization's Development Agenda, Wilfred Laurier University Press, 2009.

Basheer, S and T P Reddy, "The "Efficacy" of Indian Patent Law: Ironing Out the Creases in Section 3 (d)", SCRIPT -ed, 5(2): 232-266.

Graham, S.J.H. and D.C. Mowery (2003), "Submarines in Software: Continuation Patenting in Software in the 1980s and 1990s and its Implications for Open Source", JEL, 2003.

Economist, (1998) “The Pharmaceutical Industry”, February 21, 1998, 3-16.

Ernst, D (2002), 'Global Production Networks and the Changing Geography of Innovation Systems - Implications for Developing Countries', Journal of the Economics of Innovation and New Technology, 11(6), 497-523.

Ernst, D and L Kim (2002), 'Global Production Networks, Knowledge Diffusion and Local Capability Formation', Research Policy, 31 1417-1429. 
Falvey, R et al (2006), "Intellectual Property Rights and Innovation in Developing Countries", Review of Developing Economies, 10(4), 700-719.

Goldar et al (2010), Effects of New Patents Regime on Consumers and Producers of Drugs/Medicines in India, Report submitted to UNCTAD, Institute of Economic Growth, New Delhi, August.

Greene, W (2007), “The Emergence of India's Pharmaceutical Industry and Implications for the US Generic Drug Market". Office of the Economics Working Paper No 2007-05-A, US International Trade Commission, Washington DC.

Greenhalgh, C and M Rogers (2010), Innovation, Intellectual Property and Economic Growth, Princeton University Press.

Indian Venture capital Journal (IVCJ)(2006),"Indian Life Sciences Gathering Momentum", 3: 22-67.

James, TC (2009), Patent Protection and Innovation: Section 3(d) of the Patents Act and Indian Pharmaceutical Industry, Indian Pharmaceutical Alliance, Mumbai.

Koneru, P (1998), “To Promote the Progress of Useful Articles?: An Analysis of the Current Utility Standards of Pharmaceutical Products and Biotechnological Research Tools" 38 IDEA: The Journal of Law and Technology 625.

Linton, K C and N Corrado (2008), "A "Calibrated Approach": Pharmaceutical FDI and Evolution of Indian Patent Law, Journal of International Commerce and Economics, Vol 1, August, 163-184.

Maskus, K.E. (2008), 'Incorporating a Globalized Intellectual Property Rights Regime into an Economic Development Strategy' in K.E. Maskus (ed.) Intellectual Property, Growth and Trade, Elacvier

Maskus K.E., McDaniel C.A., (1999), "How technology got a boost from the Japanese Patent Office", in "Impacts of the Japanese patent system on productivity growth" (Japan and the World Economy 1999, 11(3), 1-17 
Mercurio, B (2010), 'Reconceptualizing the Debate on Intellectual Property Rights and Economic Development', The Law and Development Review, 3(1), Article 3. Available at http:/www.bepress.com/Idr/Vol3/1651/art3.

Odagiri, H, A. Goto, A. Sunami and R. Nelson (eds) (2010), Intellectual Property Rights, Development and Catchup, Oxford University Press.

Organization of Pharmaceutical Producers of India, OPPI (2008), "Regulatory Data Protection - A Building Block for Pharmaceutical R\&D" OPPI Position Paper.

Rai, R. K. (2009), "Effect of the TRIPS-Mandated Intellectual Property Rights on Foreign Direct Investment in Developing Countries: A Case Study of the Indian Pharmaceutical Industry", The Journal of World Intellectual Property, 11(5-6), 404431.

Rai, R.K. (2008), "Battling with TRIPS: Emerging Firm Strategies of Indian Pharmaceutical Industry Post-TRIPS”, Journal of Intellectual Property Rights, 13, 301-317.

Rothaermel F T amd A M Hess (2007), 'Building Dynamic Capabilities: Innovation Driven by Individual-, Firm-, and Network Level Effects', Organization Science, 18 (6), 898-921.

Saberwal, G (2008), "Many drug discovery and development skills are rare in India today", $\underline{\text { Mimeo. }}$

Sreeraman Vaidyanathan and Surga Thilakan (2004), "Strategies to Promote Entrepreneurial Innovation in the Indian Pharmaceutical and Biotechnology Sectors through a Legal Framework for Intellectual Property Rights", November. Indian Institute of Management Ahmedabad.

Sundaramoorthy, S, Y C Bindu, R Mehdiratta and G Saberwal (2009), "The US Patent Holdings of Homegrown Indian Biotech and Pharma Companies" Current Science, 96 (2): 252-259.

US-India Business Council and Coalition for Healthy India(2009), The Value of Incremental Pharmaceutical Innovation: Benefits for Indian Patients and Indian Business (Available at http://www.ahealthyindia.org/portal/chi/default)

Wertheimer, A, L Radican and M R Jacobs (2010), "Assessing Different Perspectives on the Value of Pharmaceutical Innovation", Southern Medical Review 3 (1), 24-28.

Zinnov (2006), Pharmaceutical Outsourcing Landscape in India. 